\title{
Hardcopy quality parameters to ensure structures detection at digital mammography*
}

Identificação de parâmetros de qualidade de impressão para a garantia da detecção de estruturas presentes na mamografia digital

Rafael Eidi Goto ${ }^{1}$, Silvio Ricardo Pires $^{2}$, Regina Bitelli Medeiros ${ }^{3}$

Abstract Objective: To develop procedures to ensure consistency of printing quality of digital images, by means of hardcopy quantitative analysis based on a standard image. Materials and Methods: Characteristics of mammography DI-ML and general purpose DI-HL films were studied through the QC-Test utilizing different processing techniques in a FujiFilm ${ }^{\circledR}$ DryPix4000 printer. A software was developed for sensitometric evaluation, generating a digital image including a gray scale and a bar pattern to evaluate contrast and spatial resolution. Results: Mammography films showed maximum optical density of 4.11 and general purpose films, 3.22. The digital image was developed with a 33-step wedge scale and a high-contrast bar pattern (1 to $30 \mathrm{lp} / \mathrm{cm}$ ) for spatial resolution evaluation. Conclusion: Mammographic films presented higher values for maximum optical density and contrast resolution as compared with general purpose films. The utilized digital processing technique could only change the image pixels matrix values and did not affect the printing standard. The proposed digital image standard allows greater control of the relationship between pixels values and optical density obtained in the analysis of films quality and printing systems.

Keywords: Hardcopy; Quality control; Contrast sensitivity; Mammography.

Resumo Objetivo: Desenvolver procedimentos que garantam a constância e qualidade de impressão das imagens digitais, mediante análise quantitativa das imagens impressas utilizando um padrão de imagem. Materiais e Métodos: Foram estudadas as características dos filmes mamográficos (DI-ML) e de uso geral (DI-HL) por meio do teste QC-Test sob diferentes processamentos utilizando a impressora FujiFilm ${ }^{\circledR}$-DryPix4000. Foi criado um software para avaliação sensitométrica que gera uma imagem digital contendo uma escala de níveis de cinza e um padrão de barras para avaliação das resoluções de contraste e espacial. Resultados: Filmes mamográficos apresentaram valores de densidade óptica máxima 4,11, enquanto os comuns apresentaram valores 3,22. A imagem digital foi desenvolvida com 33 passos de enegrecimento e um padrão de barras de alto contraste $(1$ a 30 pl/cm) para avaliação da resolução espacial. Conclusão: Verificou-se que o filme mamográfico apresenta um maior valor de densidade máxima e maior índice de contraste, comparado ao filme de uso geral. 0 processamento digital utilizado apenas alterou os valores da matriz de pixels da imagem e não influenciou o padrão de impressão. 0 padrão de imagem digital proposto permite maior controle da relação entre os valores de pixel e densidade ótica obtida na verificação da qualidade dos filmes e do sistema de impressão.

Unitermos: Impressão; Controle de qualidade; Sensibilidades de contraste; Mamografia.

Goto RE, Pires SR, Medeiros RB. Hardcopy quality parameters to ensure structures detection at digital mammography. Radiol Bras. 2013 Mai/Jun;46(3):156-162.

\section{INTRODUCTION}

Digital radiology is a reality in Brazil, allowing a range of possibilities concerning acquisition and processing of images

* Study developed at Coordination of Physics and Radiations Hygiene, Department of Diagnostic Imaging, Escola Paulista de Medicina - Universidade Federal de São Paulo (EPM-Unifesp), São Paulo, SP, Brazil. Financial support: Fundação de Amparo à Pesquisa do Estado de São Paulo (Fapesp).

1. Specialist in Medical Physics, Master, Department of Diagnostic Imaging, Escola Paulista de Medicina - Universidade Federal de São Paulo (EPM-Unifesp), São Paulo, SP, Brazil.

2. PhD, Associate Professor, Department of Information Technology in Health, Escola Paulista de Medicina - Universidade Federal de São Paulo (EPM-Unifesp), São Paulo, SP, Brazil.

3. PhD, Associate Professor, Department of Diagnostic Imaging, Escola Paulista de Medicina - Universidade Federal de São Paulo (EPM-Unifesp), São Paulo, SP, Brazil. which ultimately interfere in the generation of accurate diagnoses. In order to ensure the quality of radiologic images regardless of the utilized technology, it is of utmost importance to ensure the quality of such images presentation on films, by means of wet film processing control and dry film printing process control, as well as on monitors, by means of specific monitor quality control ${ }^{(\mathbf{1})}$.

The utilization of digital techniques and image processing is one the branches in the

Mailing Address: Rafael Eidi Goto. Rua Itinguçu, 1620, Vila Ré. São Paulo, SP, Brazil, 03658-001. E-mail: eidigoto@gmail. com.

Received March 6, 2012. Accepted after revision March 7, 2013. field of computational sciences in constant development and has aided radiologists to achieve greater accuracy in diagnoses ${ }^{(2)}$. Image processing methods play a secondary role, among them those which provide contrast enhancement with edges identification, adjustments in the brightness scale, energy subtraction and others ${ }^{(3)}$. Such parameters generate a grading of the image called lookup table (LUT), which is defined for each imaging modality by the manufacturer of the processing system.

The current dry printers are based on two technologies, as follows:

1) Without laser - Equipment with reduced contrast and spatial resolution, which 
can be divided into thermal printers and inkjet or waxjet printers. However, such systems are not the focus of this study.

2) With laser beam - Equipment with greater capacity to demonstrate small structures with greater spatial and contrast resolution. Such equipment can be divided into: a) thermal systems - equipped or not with thermal print heads, and operating by means of dye-sublimation or by means of thermal energy absorption in the rotation cylinders; b) photosensitive media - photothermal systems such as the $\operatorname{Kodak}^{\circledR}$ DryView, Fuji ${ }^{\circledR}$ FM-DP L and Konika ${ }^{\circledR}$ DryPro models.

Photothermographic systems rely on infrared laser diodes $(810 \mathrm{~nm})$, with extremely small focal spots of approximately 40 to 80 micra, allowing a resolution of 400 to $800 \mathrm{dpi}$, which are very stable light emitting sources with modulated and accurate emission power with a wide dynamic range (several gray levels) and extremely high image production speed. Figure 1 shows a generic laser modulation model.

The device emits a laser beam into the acousto-optic modulator where such beam scans the rolling cylinders in lines through polygonal mirrors, F-theta lenses and cylindrical mirrors.

Figure 2 represents the laser printer film construction structure, as well as the dry processing structure in the image recording.

The film comprises three layers as follows: the antiscattering layer, coating layer and photothermographic layer composed of silver crystal halides where the image formation occurs by means of the transformation of silver ions into silver metal. A polyester plastic base sustains the film.

Photothermographic printers rely on infrared laser radiation to create a kind of "latent image" on the sensitive layer of the film, transforming the silver metal $\mathrm{Ag}^{+}$into silver metal $\mathrm{Ag}^{0}$ which will be converted into visible image by means of a thermal process with modulated densities of black silver metal particles. The thermal energy acts on the latent image to be developed by means of a catalytic process, which transforms the "silver behenate crystals" neighboring the silver metal atoms.

According to the manufacturers, printing quality control tests should be performed at every change of film box, as well

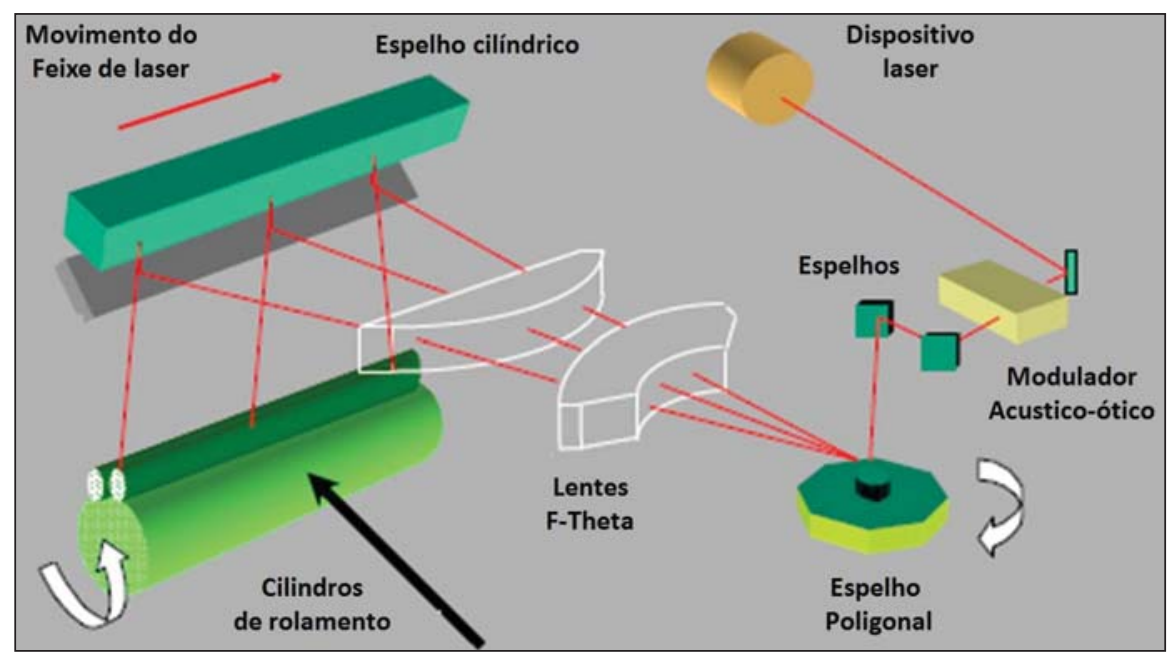

Figure 1. Laser modulation generic model. Generic scheme of modulated laser beam for printers.

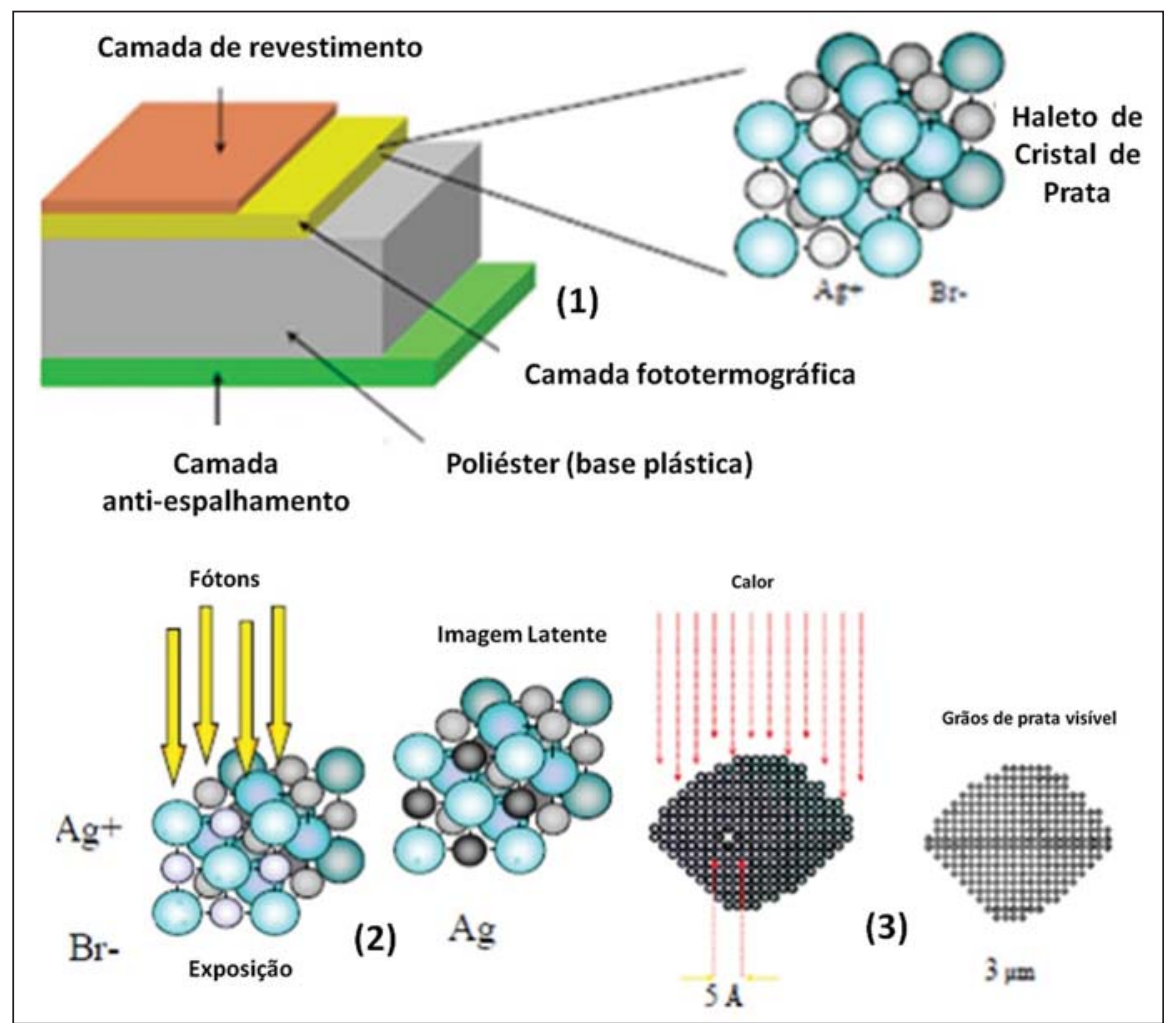

Figure 2. Laser printer film construction structure, as well as the dry processing structure in the image recording. Representation of laser printer specific radiographic film and model of silver metal formation after exposure to laser photons by means of catalytic heat process.

as after equipment maintenance interventions, and periodically, according to user installations. In general, such tests utilize a digitally modulated non-linear step wedge scale to reproduce a pattern similar to the Hurter \& Driffield (H\&D) curve.

Comparative studies of film processors and dry printers have been undertaken with the purpose of identifying technological ad- vantages in image acquisition ${ }^{(4)}$. A study utilizing digital dental images has compared hardcopy images produced in professional thermal equipment, plain inkjet printers and images visualized on displays, and concluded that there are significant differences between such images ${ }^{(5)}$.

Comparative tests of digital mammography images were performed with dry and 
wet laser printers, concluding that both systems can correctly represent the evaluated structures, but preference should be given to dry printers which avoid the liquid chemical waste $^{(4)}$. Other studies have demonstrated that radiographs should not be directly exposed neither to the sun or heat $>35^{\circ} \mathrm{C}$, since changes in the film optical density may occur; so it is advisable that radiographs are stored in envelopes in order to minimize such effect ${ }^{(6,7)}$. In digital mammography, the accurate reproduction on film of the image observed on the display is essential to ensure that tiny structures that may be present can be visualized ${ }^{(\mathbf{8 , 9})}$.

The present study is aimed at developing procedures to ensure printing constancy and quality of digital radiological images, by means of subjective and objective analysis of printed images using an image standard containing a gray scale according to international recommendations.

\section{MATERIALS AND METHODS}

In the present study, the following apparatuses were utilized: a CIRS ${ }^{\circledR} 011 \mathrm{~A}$ phantom; a Philips ${ }^{\circledR}$ MD4000 ${ }^{\mathrm{TM}}$ mammography system; a CR FujiFilm ${ }^{\circledR}$ FCR Profect $\mathrm{One}^{\mathrm{TM}}$ system equipped with a HR-BD 18 $\times 24 \mathrm{~cm}^{2}$ imaging plate; a Drypix $4000^{\mathrm{TM}}$ printer; a specific Clinton ${ }^{\circledR}$ DL-3000, 3.0 Mpixels monitor; and a Konex ${ }^{\circledR}$ KO-NM4 film viewer were utilized. Initially, an image of the CIRS $^{\circledR}$ phantom was acquired and submitted to three different processing procedures frequently utilized for the CR Fuji system, generating three hardcopy images. Concomitantly, a software was developed in the Delphi $7^{\circledR}$ (Borland $^{\circledR}$ ) which generates a new image standard in order evaluate hardcopy quality. Both mammography-specific films and general-purpose films were utilized. The images analysis was performed on the monitor and on the film viewer.

The following processing techniques were utilized: the one recommended by the manufacturer as the Japanese standard for breast imaging (P1); the most utilized by specialists in Brazil for contrast enhancement with edges identification (P2); and the procedure that provides increased contrast (P3). Such digital filters were applied to the previously selected image and printed un- der three LUT curve adjustment levels, with the purpose of evaluating the LUT influence on each processing. The quality of the simulated images was evaluated under different printing patterns obtained with the utilization of different digital filters with different LUT curves of the printers, automatically, by means of the test recommended by the manufacturer, named QC-Test. Such a test consists in evaluating the degree of the film darkening, based on a standard established by the manufacturer, where a curve similar to the sensitometric curve of conventional radiologic films is reproduced. The values $-3,0,2$ and 4 of adjusted maximum optical density were available on the printer control pad, and the results of the printed images were measured with a Victoreen 07443 optical densitometer (Nuclear Associates) for comparative purposes.

On the monitor, the mean pixel values and standard deviations were measured on the regions of interest (ROI) with a rectangular area of $50 \pm 5 \mathrm{~mm}^{2}$ of the structures 14 to 18 , and a circular area of $30 \pm 3 \mathrm{~mm}^{2}$ on the reference zone of the phantom. Such areas could encompass practically the entire structure of interest. For the printed images, the optical densities were measured five times at each corresponding point where it was possible to find a relation between optical density, pixel value and luminous intensity. The images were printed on DI-HL films (general purpose films) and DI-ML (specific for mammography) which allows the acquisition of images with greater contrast and maximum density. The hardcopy quality was evaluated by three medical physicists and two radiology technologists who visually analyzed the quantity and size of the smallest structures visualized on the printed images from the phantom.

Concomitantly, a software was developed for sensitometric evaluation which generates a standard image containing a gray scale and a bar pattern for evaluation of spatial and contrast resolutions. Such image may be either in the TIFF format (tagged image file format) or DICOM format (digital imaging and communications in medicine format) of 8 or 16 bits, with a $2.5 \mathrm{k} \times$ $2 \mathrm{k}$ matrix, and 33-step wedge (base plus 32 levels) and a bar pattern with two line pairs per centimeter $(\mathrm{pl} / \mathrm{cm})$ up to $30 \mathrm{pl} / \mathrm{cm}$

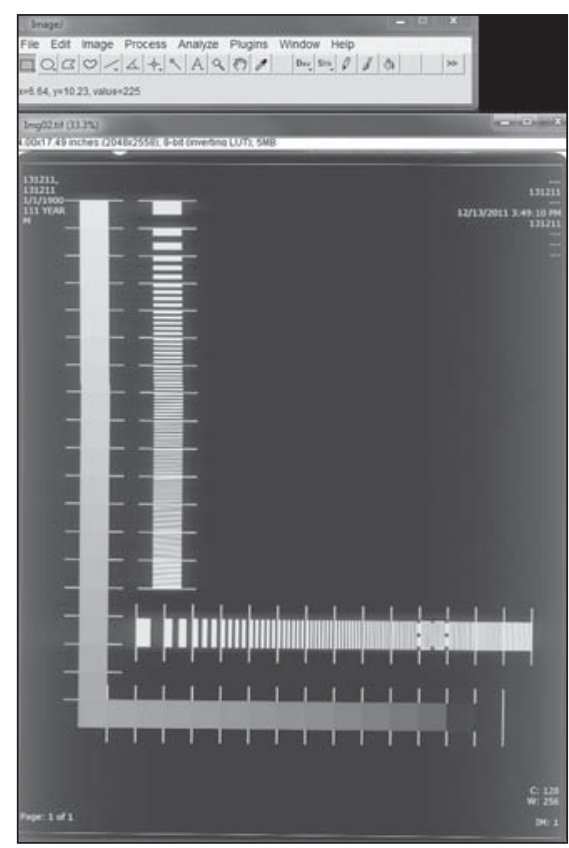

Figure 3. Computer generated image by the Delph software. ROI selection on the image with ImageJ.

in the two directions of the film, for spatial resolution evaluation, as shown on Figure 3. Such proposed image standard was compared with the internationally recommended test image standards recommended by international organizations such as American Association of Physicists in Medicine (AAPM), National Electrical Manufacturers Association (NEMA) and International Atomic Energy Agency (IAEA), besides the manufacturer's standards. All the images were printed according to the LUT curve determined by the manufacturer, where the optical density of each step wedge on the generated standard image was read and compared with the optical density values observed on the monitor.

The image developed for printers evaluation contains horizontal and vertical high contrast bars, ranging between 1 and $30 \mathrm{pl} /$ $\mathrm{cm}$, where a ROI can be selected on each one of the image intervals. The same method was utilized for the contrast scale.

\section{RESULTS}

Table 1 presents the results obtained on the images printed on DI-HL (general purpose) films and DI-ML (mammography specific) films. No interobserver disagreement was observed in relation to size and number of visualized structures. 
Table 1 Structures visualized for different combinations of processing and LUT on Fuji DI-HL and DI-ML films.

\begin{tabular}{|c|c|c|c|c|}
\hline Film & $P$ & LUT & $\begin{array}{l}\text { Vizualized } \\
\text { structures }\end{array}$ & $\begin{array}{c}\text { Smallest } \\
\text { vizualized } \\
\text { structures }\end{array}$ \\
\hline \multirow{9}{*}{ DI-ML } & \multirow{4}{*}{ P1 } & 1 & 29 & $3,22,29$ \\
\hline & & 2 & 27 & $4,22,28$ \\
\hline & & 3 & 29 & $3,22,29$ \\
\hline & & 1 & 29 & $3,22,29$ \\
\hline & \multirow[t]{3}{*}{ P2 } & 2 & 30 & $3,22,30$ \\
\hline & & 3 & 30 & $3,22,30$ \\
\hline & & 1 & 30 & $3,22,30$ \\
\hline & \multirow[t]{2}{*}{ P3 } & 2 & 30 & $3,22,30$ \\
\hline & & 3 & 30 & $3,22,30$ \\
\hline \multirow{9}{*}{ DI-HL } & \multirow{4}{*}{ P1 } & 1 & 28 & $3,22,28$ \\
\hline & & 2 & 28 & $3,22,28$ \\
\hline & & 3 & 29 & $3,22,29$ \\
\hline & & 1 & 29 & $3,22,29$ \\
\hline & \multirow[t]{3}{*}{ P2 } & 2 & 29 & $3,22,29$ \\
\hline & & 3 & 30 & $3,22,30$ \\
\hline & & 1 & 30 & $3,22,30$ \\
\hline & \multirow[t]{2}{*}{ P3 } & 2 & 30 & $3,22,30$ \\
\hline & & 3 & 30 & $3,22,29$ \\
\hline
\end{tabular}

P, processing type.

Results from the QC-Test recommended by the manufacturer for maximum densities of -3, 0, 2 and 4 are presented on Figure 4.

The maximum density value was changed on the printer and the test recommended by the manufacturer, the QC-Test, was performed, with evaluation of the optical density values for each image. Similar results were observed for the different adjustments. The printer utilizes a processing method that is similar to the classical result of the H\&D curve.

The results from the comparison between the HL and ML films are presented on Figure 5.

Once the QC-Test result was known, the ML (mammography specific) film and the HL (general purpose) film responses were compared. An adjustment was performed in the linear region in order to determine the difference in the contrast ratio between HL and ML films.

Figure 6 presents the result with the pattern utilized for printing tests recommended by AAPM (PQC-Pattern), which allows for the evaluation of contrast and spatial resolutions of the printing system. It shows the behavior of the optical density variation as a function of the steps proposed by TG-18-PQC, where it is possible to perform an adjustment in the linear region in order to track variations in the contrast ratio along time.

The sensitometric parameters of the films obtained with the proposed image standard (Figure 3 ) and the AAPM image were evaluated according to the IAEA recommendations. The results are shown on Table 2.

\section{DISCUSSION}

The gains in terms of perception of tiny structures of interest with great differences in contrast, or of structures with equivalent contrast, are examples of the increasing preoccupation in improving the technology involved in the quality of radiological images $^{(\mathbf{1 0 , 1 1})}$. As the radiological image printing technology is considered, studies indicate that dry imaging films have different chemical reagents on their surface when compared with wet (conventional) films ${ }^{(\mathbf{6})}$. In practice, one observes that if such films get wet either by sweat from hands or by excess air moisture, imaging artifacts may be generated, which calls for strict control of ambient temperature, relative air moisture, storage and manipulation, according to the manufacturer's recommendations.

Practically most of the dry printers for radiology have some type of quality control or calibration test. In the case of the Drypix $4000^{\mathrm{TM}}$ printers, the QC-Test demonstrated to be useful only for comparative analysis of the radiographic films response. It was

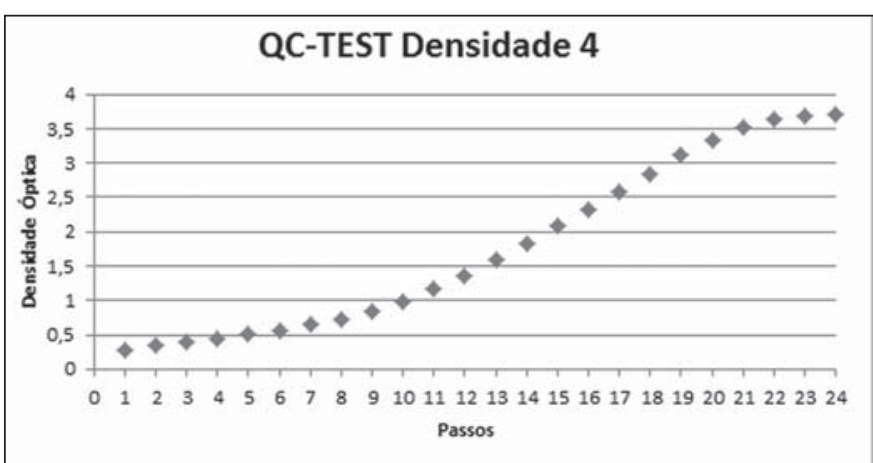

QC-TEST Densidade 2

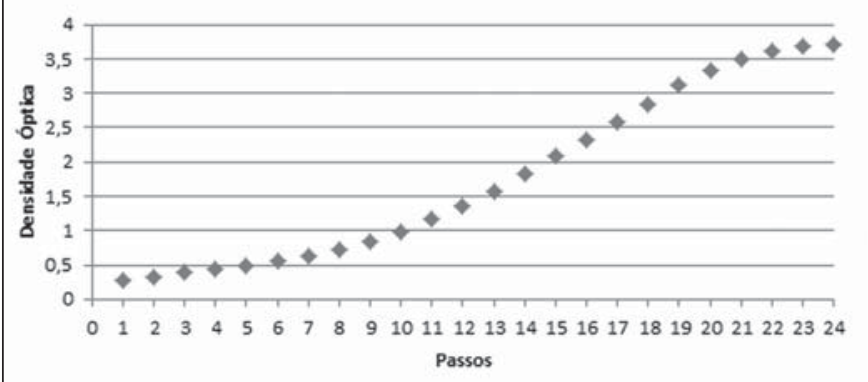

\section{QC-TEST Densidade 0}

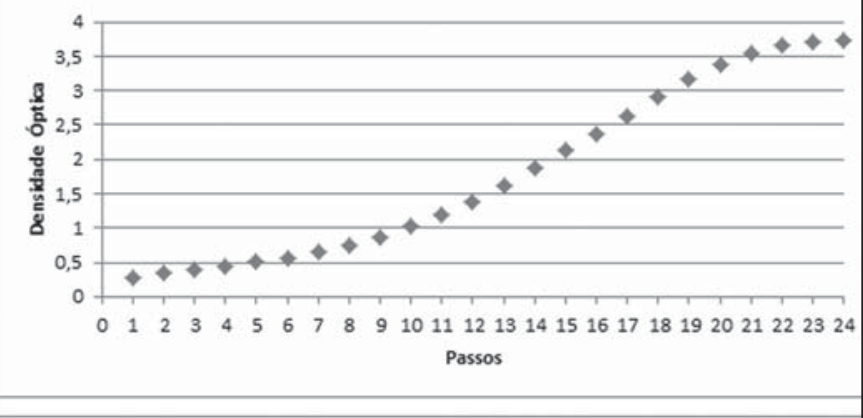

QC-TEST Densidade -3

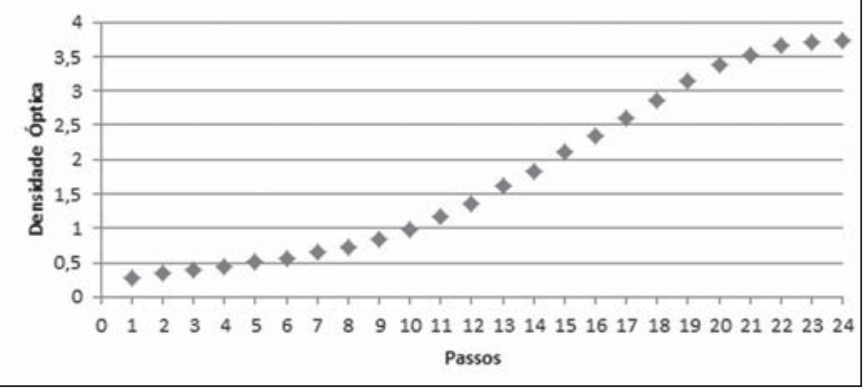

Figure 4. QC-Test calibration curves utilizing different values for maximum density. 


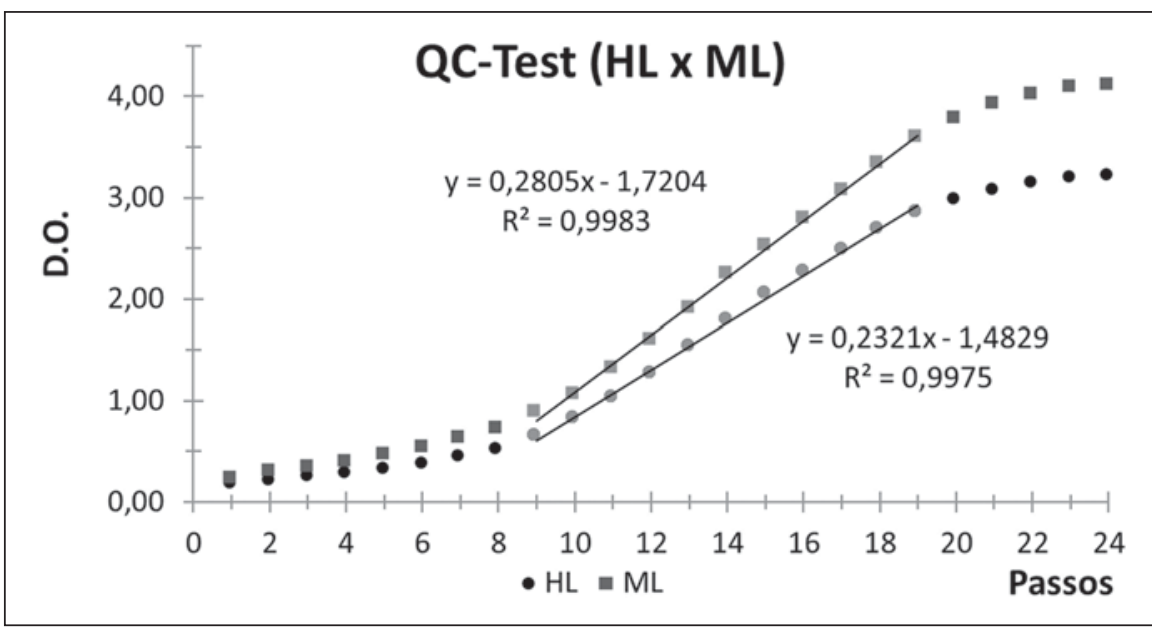

Figure 5. Comparison of performance between mammography specific printing film and general purpose film.

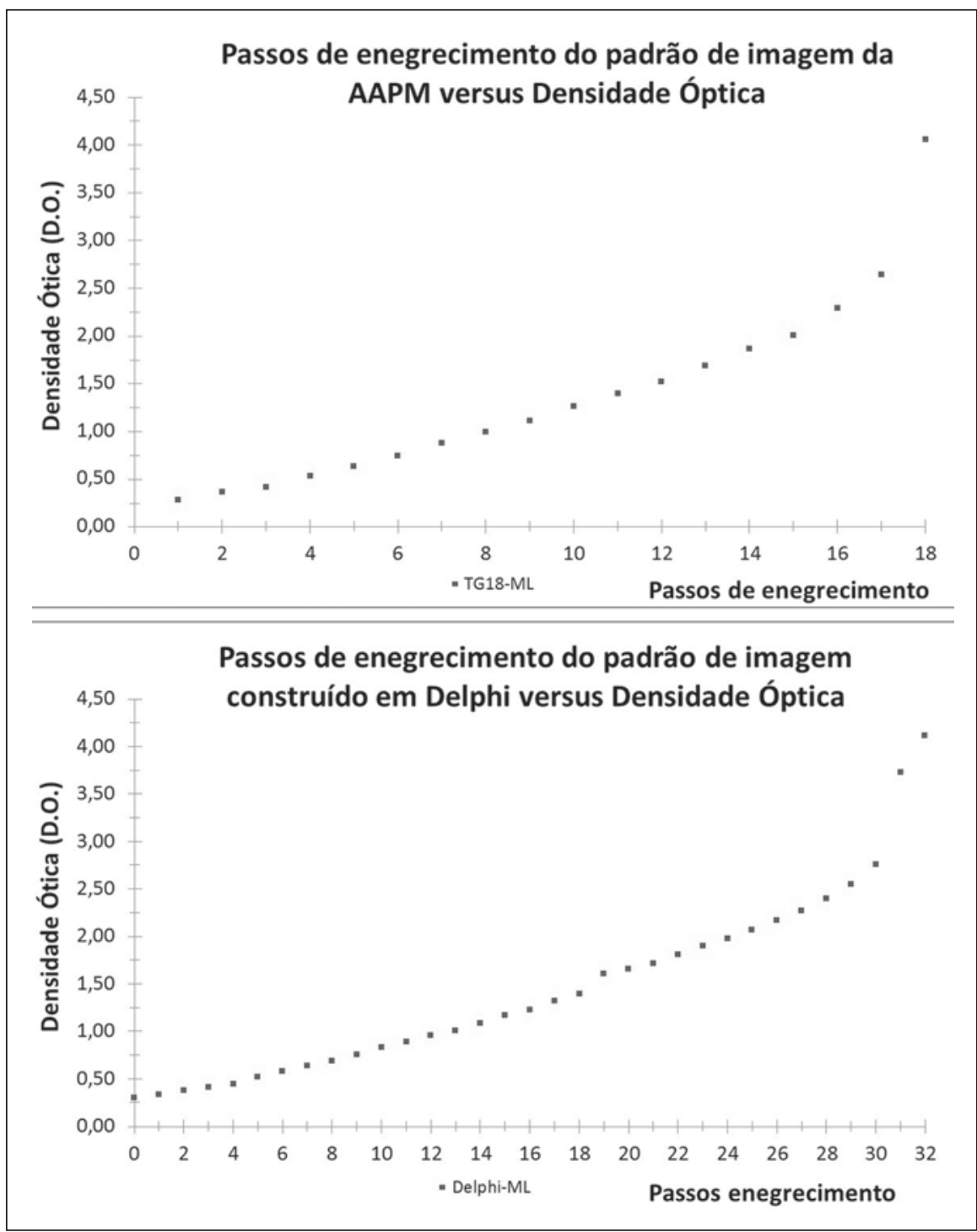

Figure 6. Behavior of optical density variation as a function of steps proposed by TG-18 PQC and computationally built with Delphi. Steps versus optical density of the PQC image of AAPM.
Table 2 Results from evaluation according to IAEA with images from AAPM and images generated with Delphi.

\begin{tabular}{ccc}
\hline Parameter & Delphi & AAPM \\
\hline$D_{\max }$ & $4.05 \pm 0.01$ & $4.07 \pm 0.01$ \\
DD & $1.71 \pm 0.01$ & $1.64 \pm 0.01$ \\
MD & $1.22 \pm 0.01$ & $1.32 \pm 0.01$ \\
Base + fog & $0.31 \pm 0.01$ & $0.29 \pm 0.01$ \\
\hline
\end{tabular}

$\mathrm{D}_{\max }$, maximum density; $\mathrm{DD}$, density difference; $\mathrm{MD}$ mean density.

observed that the DI-ML film indicated for printing of mammography images presented an inferior response as compared with that of the DI-HL film in terms of detected structures in the case of the combination P1 with LUT 1 and 2, but the response was superior in the cases of $\mathrm{P} 2$ with LUT 2 and P3 with LUT 3 combinations. This indicates that microcalcifications represented at LUT 2 were missed on the hardcopy. On the other hand, on the processed images observed on the monitor screen, there was no compromise of the information detection, suggesting that the contrast scale is not affected by the digital processing, but is affected by the LUT selected in the printing process. Additionally, depending on the utilized processing technique, noise may be added or increased, generating printed image degradation. It was observed that that varying the maximum density level for the $-3,0,2$ and 4 values does not cause any significant impact on the QC-Test response, indicating that such function is blocked by the manufacturer, so that adjustments are not allowed. However, it was observed that the DI-ML film presents higher maximum optical density than that of the DI-HL film, as well as greater inclination in the linear region, suggesting a higher contrast index by analogy with the sensitometric analysis on conventional films. However, it was possible to observe that the linear zone considered as the usable region of the film for imaging contrast levels remains unchanged, indicating that there is no variation regarding latitude.

Following the recommendations of NEMA, the proposed quality control procedure is only visual, therefore subjective; on the other hand, the evaluation according to the IAEA recommendations allows 
a quantitative evaluation based on reference values adopted at the beginning of the utilization of the printing system. The procedure was performed with the gray scale proposed by IAEA and also with the image generated by the Delphi $7{ }^{\circledR}$ software created for the present study, producing different results, which leads to the establishment of new acceptable variation intervals for intervention. Following the example of the AAPM results, which indicates the response in film darkening with change of the pixel value at each step of the gray scale ${ }^{(7)}$, the chart obtained image proposed in the present study also indicates such response, allowing its utilization in the IAEA recommended test. Thus, one realizes that the test proposed in the present study is very similar to the test proposed by AAPM, however, the greater number of image darkening steps provide a more accurate basis for the control of the printing system variables. Additionally, it was observed that AAPM attempts to obtain linear increments at each image darkening step and, from the step with pixel value equal zero, there are 17 increments up to the highest pixel value, in a total of 18 darkening steps. The curves presented by the AAPM image and by the proposed image are also similar to the GSDF (gray-scale standard display function) curve that is the response in monitors luminosity to each pixel associated with the image. Thus, it is possible to observe that an approximation between the printing system and the image presented on the monitor screen is attempted with the selection of LUT.

It is possible that with some calibration of the printing system, the hardcopy image becomes very similar to the image visualized on the monitor screen and, once such objective is achieved, no differences would be observed in the detection of signals, provided that the professionals were duly trained.

Breast cancer is one of the most frequent types of cancer, with higher prevalence among women ${ }^{(\mathbf{1 2})}$. Despite the high incidence of such disease over the past years, a decrease in breast cancer mortality has been observed as a result of the increase in early detection and in the availability of new imaging technology resources $^{(12,13)}$. The diagnostic performance of digital mammography in the detection of breast cancer has demonstrated to be comparable or superior to that of conventional mammography ${ }^{(\mathbf{1 4})}$. The Ministry of Health Ordinance No. 531 dated March 03, 2012 established that digital mammography reporting is to be carried out on monitors, and that hardcopy images or recordings on magnetic media are to be made available to the patients. This validates the relevance of quality control to guarantee the reliability of printed digital images. The screening for breast lesions by means of digital files may present a better performance as the typical limitations of the radiographic films utilized for printing such images are considered $^{(14)}$

Finally, another point that should be highlighted is the fact that the Brazilian radiology literature has recently emphasized the significant role played by imaging methods in the improvement of breast di$\operatorname{agnosis}^{(15,16)}$.

\section{CONCLUSIONS}

The present study corroborated the understanding of the features and operation of digital radiology printers, and allowed the development of a software which generates a new image standard for assessment of constancy and quality of hardcopy images. Such new image parameters were compared with the image standards proposed by NEMA, AAPM and IAEA by means of subjective and objective analyses. Such new parameters allow a greater control of the relation between the pixel value and the obtained optical density value in the evaluation of the quality of films and printing system.

The DI-ML (mammography specific) film presented a higher maximum density value and higher contrast index as compared with the general purpose DI-HL film, but it did not present a better performance in the detection of structures of interest in the mammography phantom with the images processing and printing techniques utilized in the present study.

The validation of printing systems quality presented constancy over the whole period of evaluation, demonstrating compliance with international standards. However, because of the great difference ob- served in the results of the tests proposed by the competent bodies and those proposed by the manufacturer, the QC-TEST must be performed and analyzed only for comparative purposes as the conventional and sensitometric evaluation methods do not have the same meaning in the evaluation of digital images.

The quality evaluation based on the NEMA standard is qualitative and relative, as it depends on the interpretation of the investigator who makes the analysis of the hardcopy image. Such type of analysis is certainly subjective and is not sufficient for medical applications, differently from the IAEA recommendations, which rely on images from AAPM or any other gray scale, where there is method of quantitative evaluation which may indicate the need for intervention. Therefore, one concludes that the image generated in the present study can be utilized for quantitative analysis.

It is also possible to conclude that the digital processing only changes the values of the pixel matrix of the digital image and does not influence the printing standard. As the darkening is related with the pixel values, the ideal LUT curve for utilization by the printing systems should be that whose response in tests of the pixel value versus optical density is closer to GSDF, providing a printed image faithful to the image visualized on the monitor screen.

\section{REFERENCES}

1. Medeiros GS, Silva AMM. Controle de qualidade de monitores para visualização de imagens radiológicas digitais. III Simpósio de Instrumentação e Imagens Médicas; 2007 Nov 7-9; São Carlos, SP, Brasil.

2. Figueiredo JCB, Furuie SS, Gutierrez MA, et al. Um modelo prático para o uso da telemedicina. VII Congresso Brasileiro de Informática em Saúde; 2000 Out 14-18; São Paulo, SP, Brasil.

3. Reiner BI, Siegel EL. SCAR University 2003, Educating healthcare professionals for tomorrow's technology. SCAR Annual Meeting. 2002;1:73113.

4. Al Khalifah K, Brindhaban A, Al Baloul G, et al. Optical density changes in dry-processed films. Radiol Technol. 2007;79:9-16.

5. Gijbels F, Sanderink G, Pauwels H, et al. Subjective image quality of digital panoramic radiographs displayed on monitor and printed on various hardcopy media. Clin Oral Investig. 2004; 8:25-9.

6. Gahleitner A, Kreuzer S, Schick S, et al. Dry versus conventional laser imagers: film properties and image quality. Radiology. 1999;210:871-5.

7. Samei E, Badano A, Chakraborty D, et al. As- 
sessment of display performance for medical imaging systems: executive summary of AAPM TG18 report. Med Phys. 2005;32:1205-25.

8. Obenauer S, Hermann KP, Marten K, et al. Soft copy versus hard copy reading in digital mammography. J Digit Imaging. 2003;16:341-4.

9. Sociedad Española de Física Médica, Sociedad Española de Protección Radiológica, Sociedad Española de Radiología Médica. Protocolo español de control de calidad en radiodiagnóstico. Revisión 2011. SEFM, SEPR; 2012.

10. Nobre LF, Von Wangenheim A, Azevedo-Marques PM. Radiological displays: a necessity or luxury? Radiol Bras. 2012;45(4):v-vi.
11. Pinto M, Pedro M, Santos A, et al. Display quality control based on luminance measurements in post-processing units at imaging diagnosis centers. Radiol Bras. 2012;45:29-34.

12. Miranda CMNR, Santos CJJ, Maranhão COM et al. Is multislice computed tomography an important tool for breast cancer staging and followup? Radiol Bras. 2012;45:105-12.

13. Brasil. Ministério da Saúde. Instituto Nacional de Câncer. Estimativa 2010: incidência de câncer no Brasil. Rio de Janeiro, RJ: INCA; 2013.

14. Urban LABD, Schaefer MB, Duarte DL, et al. Recommendations of Colégio Brasileiro de Radiologia e Diagnóstico por Imagem, Sociedade
Brasileira de Mastologia, and Federação Brasileira das Associações de Ginecologia e Obstetrícia for imaging screening for breast cancer. Radiol Bras. 2012;45:334-9.

15. Calas MJG, Gutfilen B, Pereira WCA. CAD and mammography: why use this tool?. Radiol Bras. 2012;45:46-52.

16. Alvares BR, Freitas CHA, Jales RM, et al. Mammographic density in asymptomatic menopausa women: correlation with clinical and sonographic findings. Radiol Bras. 2012;45:149-54. 